\title{
Processo de Infecção e Formação de Mancha em Grãos de Aveia Branca com Níveis Diferenciados de Resistência para Pyrenophora chaetomioides"
}

\author{
Carla A. C. Bocchese ${ }^{1}$, José A. Martinelli ${ }^{1}$, Luiz C. Federizzi ${ }^{2}$ \& Carlos R. E. Rosa ${ }^{1}$ \\ ${ }^{1}$ Departamento de Fitossanidade; ${ }^{2}$ Departamento de Plantas de Lavoura, Faculdade de Agronomia, Universidade Federal do \\ Rio Grande do Sul, Cx. Postal 776, CEP 90012-970, Porto Alegre, RS, \\ E-mail: jamfito@ufrgs.br \\ (Aceito para publicação em 03/07/2006)
}

Autor para correspondência: José Antônio Martinelli

BOCCHESE, C.A.C., MARTINELLI, J.A., FEDERIZZI, L.C. \& ROSA, C.R.E. Processo de infecção e formação de mancha em grãos de aveia branca com níveis diferenciados de resistência para Pyrenophora chaetomioides. Fitopatologia Brasileira 31:284-290. 2006.

\begin{abstract}
RESUMO
A mancha-negra dos grãos de aveia branca, cujo principal agente causal é Pyrenophora chaetomioides, é caracterizada pelo escurecimento de seus tecidos superficiais e pode ocasionar redução na qualidade e valor dos mesmos para a indústria alimentícia. Para melhor entender o processo de infecção e formação de manchas os objetivos deste trabalho foram i) Determinar o período de maior suscetibilidade dos grãos à formação de manchas por $P$. chaetomioides nos componentes florais da aveia; ii) determinar os diferentes níveis de resistência dos genótipos de aveia OR 2, ER 20877-2, UFRGS 995004-2, UPF 95204-2, UFRGS 16, UFRGS 9912002-2, UFRGS 999007-5, UFRGS 998013-3, UPF 16, UFRGS 9990221, UFRGS 995058-3, UFRGS 15, UFRGS 17, UFRGS 19 e UFRGS 997005-2 à mancha-negra e sua correlação quanto à infecção dos grãos; iii) avaliar o efeito do controle químico na expressão da doença durante a fase de formação de grãos. Em laboratório, avaliou-se o percentual de grãos manchados e a incidência de $P$. chaetomioides nos componentes florais, enquanto que, a campo, avaliaram-se o rendimento e peso do hectolitro dos grãos. Nos estádios de grão leitoso e massa é quando ocorre a maior incidência de $P$. chaetomioides nos componentes florais. Os genótipos diferiram com relação ao sintoma da mancha-negra e incidência, mas não houve correlação entre estas duas variáveis. O controle químico na floração reduziu apenas $21 \%$ da incidência do fungo nas sementes, em relação à testemunha. Apesar disso, não foi suficiente para reduzir a formação das manchas e nem aumentar o rendimento que compensasse o seu custo.
\end{abstract}

Palavras-chave adicionais: controle químico, fungicida, mancha-negra.

\begin{abstract}
Infection process and spot development on kernels of white oats with differentiated levels of resistance against Pyrenophora chaetomioides.

The black spots of oat (Avena sativa) grains, caused mainly by Pyrenophora chaetomioides, is characterized by the darkening of their superficial tissues, with reduction in their quality and value for the industry. In order to understand the infection process and formation of kernel spots the objectives of this work were i) to determine the period of kernel's susceptibility during their spot formation by P. chaetomioides on the floral components; ii) to determine the different levels of resistance of 15 oat genotypes to black spot and its correlation with kernel infection; iii) to assess the effect of chemical control on the expression of the disease during the period of kernel formation. In the laboratory, the percentage of spotted grains and the incidence of $P$. chaetomioides in the floral components was evaluated, whereas in the field, yield and industrial weight were measured. Milk and dough stages had the largest incidences of $P$. chaetomioides in the floral components. The genotypes differed with regard to the black spot symptom on the kernel as well as with the incidence, but no correlation between these two variables was observed. Chemical control during the flowering stage reduced in $21 \%$ the incidence of the fungus in the seed in relation to the control. Despite of this, chemical control was neither efficient enough to reduce spot formation nor to increase yield to compensate its cost.
\end{abstract}

Additional keywords: chemical control, fungicide, black spot of oat.

\section{INTRODUÇÃO}

A mancha-negra nos grãos de aveia branca (Avena sativa L.), cujo principal agente causal é Pyrenophora

*Parte da tese de Doutorado do primeiro autor. Universidade Federal do Rio Grande do Sul. Porto Alegre RS. 2000. chaetomioides Speg., aumentou sua freqüência e intensidade nos últimos anos devido a mudanças nas práticas culturais. Dentre elas, destacam-se a utilização de aveia como cultura de cobertura do solo para semeadura direta sem rotação adequada e o emprego de cultivares suscetíveis. $\mathrm{O}$ agravamento do problema é devido à permanência dos restos de cultura de aveia infectados por $P$. chaetomioides os 
quais constituem uma das principais fontes de inóculo para esta moléstia.

O maior dano associado a este patógeno é a redução da qualidade dos grãos e das sementes, o que ocorre mesmo com baixa severidade sobre as folhas no campo (Rosa et al., 2003). A qualidade da aveia é especificada em função do destino que será dado aos seus grãos. A indústria alimentícia fixa limites sobre diversos parâmetros, entre eles está o percentual de grãos descascados manchados (CBPA, 2003). O aumento da intensidade da mancha nos grãos tem ocasionado a rejeição de inúmeros lotes de grãos de aveia, com prejuízos para os produtores.

A localização do micélio de $P$. chaetomioides é superficial e limitada aos três tecidos do pericarpo. Este fungo consegue penetrá-los facilmente, porém, não tem habilidade para transpô-los, pois na testa da cariopse de aveia, encontra a barreira para sua penetração (Bocchese, 2000). Turner \& Millard (1931) descreveram o micélio de Pyrenophora spp. dentro dos tecidos da semente como escuro, espesso, muito septado, irregular, intracelular e com viabilidade por longo tempo. Bocchese et al. (2001), em trabalho sobre a especificidade de $P$. chaetomioides nos tecidos da semente de aveia, relataram a associação entre a intensidade das manchas e a densidade de micélio.

Apesar do aumento da importância econômica do cultivo da aveia branca para produção de grãos de alta qualidade e a ampla distribuição desta moléstia nas principais áreas de cultivo no sul do Brasil, relativamente poucos trabalhos sobre $P$. chaetomioides têm sido desenvolvidos na busca de novos conhecimentos que possam ser inseridos nas atuais práticas de manejo. Hipotetiza-se que o processo de infecção e colonização por $P$. chaetomioides possa ocorrer logo após a emissão das panículas, onde este patógeno ocasiona manchas em todos os componentes florais de aveia branca. A determinação da época de maior suscetibilidade à infecção e formação da mancha nos grãos durante seu desenvolvimento, no entanto, poderá oferecer subsídios importantes ao controle químico de $P$. chaetomioides para produção de grãos com qualidade industrial e sementes sadias.

O manejo da mancha-negra através do controle químico tem se mostrado pouco eficazna redução do inóculo em sementes e folhas, visto que o tratamento das sementes é prejudicado pela presença da casca aderida ao grão, o que dificulta a translocação do ingrediente ativo do fungicida, necessária para otimizar a eficácia do produto. Por outro lado, o tratamento foliar com fungicida ainda é efetuado pelos produtores quando há necessidade de controle de ferrugem e/ou quando a mancha-negra encontra-se com altos níveis de severidade nas folhas. Esse fato dificulta o controle efetivo desta fitodoença, já que não há correlação entre a severidade nas folhas e incidência de P. chaetomioides nos grãos (Rosa et al., 2003).

Sabesta et al. (1995) relataram a ocorrência de níveis variáveis de resistência à mancha foliar por $P$. chaetomioides em cultivares de aveia. No Brasil, o estudo do comportamento das cultivares de aveia à mancha foliar restringe-se aos trabalhos de Lângaro (2000) e Bocchese et al. (2003), onde a presença de variação nos graus de resistência também foi observada, desde média até muito baixa resistência, nas cultivares de aveia avaliadas. Não existe até o momento classificação de cultivares de aveia quanto à resistência à mancha-negra dos grãos ocasionada por $P$. chaetomioides, embora a seleção de cultivares com esta característica seja necessária para uso nos programas de melhoramento genético. Os objetivos deste trabalho foram i) determinar o período de suscetibilidade dos grãos a formação de manchas e de maior incidência de $P$. chaetomioides nos componentes florais desde a emissão da panícula até a maturação fisiológica; ii) determinar os diferentes níveis de resistência de 15 cultivares de aveia à mancha-negra e sua correlação quanto à infecção dos grãos; iii) avaliar o efeito do controle químico na expressão da doença em diferentes épocas de aplicação.

\section{MATERIAIS E MÉTODOS}

\section{Local e Período}

Este trabalho foi realizado no Departamento de Fitossanidade, Faculdade de Agronomia e na Estação Experimental Agronômica (EEA) da UFRGS, município de Eldorado do Sul, no período de janeiro de 2001 a abril de 2003. A EEA está localizada na região ecofisiográfica da Depressão Central. O clima neste local é subtropical úmido de verão quente, variedade específica "Cfa". O solo pertence à Unidade de Mapeamento Arroio dos Ratos, classificado como laterítico hidromórfico (Mello et al., 1996). De acordo com o sistema brasileiro de classificação, caracteriza-se como um plintossolo (Camargo et al., 1987). O sistema de plantio utilizado foi o de plantio direto em área de rotação de culturas, tendo sido precedida pela cultura de milho no verão e aveia no inverno anterior. A densidade de semeadura foi de 300 sementes aptas por $\mathrm{m}^{2}$. $\mathrm{O} \mathrm{pH}$ do solo na área do plantio estava ajustado para 6,5 e os níveis de fósforo e potássio de acordo com as recomendações técnicas para a cultura. Nos estádios de duas a cinco folhas, foram realizadas aplicações de nitrogênio em cobertura, com doses de $40 \mathrm{~kg}$ de N/ha.

\section{Origem das Sementes e análise do percentual de mancha e infecção}

As 15 cultivares/linhagens de aveia utilizadas neste trabalho foram escolhidas após uma avaliação visual preliminar de seus grãos dentre um grande número de genótipos disponíveis no programa de melhoramento da Universidade Federal do Rio Grande do Sul. A análise do percentual de mancha foi baseada na observação visual com quatro amostras contendo 100 grãos para cada genótipo. Para tanto, os grãos, foram descascados e classificados em dois grupos: não manchados ( $0-10 \%$ de intensidade de manchas) e manchados (10-50\% de intensidade de manchas), segundo gradiente de intensidade das manchas, estabelecido por Bocchese et al. (2001).

O percentual de infecção de todos os genótipos testados foi avaliado através da incidência de $P$. chaetomioides em 400 grãos, quando incubados sobre meio de cultura BDA 
em placas de Pétri, sob temperatura controlada a $23 \pm 3{ }^{\circ} \mathrm{C}$ e com fotoperíodo de $12 \mathrm{~h}$. Neste experimento utilizaram-se placas de Pétri, com 10 sementes cada, sendo 40 placas para cada genótipo testado. Os genótipos utilizados neste trabalho foram OR 2, ER 20877-2, UFRGS 995004-2, UPF 95204-2, UFRGS 16, UFRGS 9912002-2, UFRGS 999007-5, UFRGS 998013-3, UPF 16, UFRGS 999022-1, UFRGS 995058-3, UFRGS 15, UFRGS 17, UFRGS 19 e UFRGS 997005-2.

\section{Infecçãoeformaçãodamanchaduranteodesenvolvimento dos grãos}

Neste trabalho foram selecionados seis genótipos de aveia branca UFRGS 19, UFRGS 16, UFRGS 9990004-2, ER 20877-2, UFRGS 998013-3 e UFRGS 995058-3 por terem se mostrado representativos dos demais genótipos testados, apresentando níveis diferenciados de resistência à infecção e a formação de manchas. O percentual de infecção foi avaliado através da incidência de $P$. chaetomioides nos componentes florais (glumas, páleas, lemas e carpelos) oriundos de 160 flores de cada genótipo. Após a separação dos componentes florais, estes foram incubados, isoladamente, sobre meio de cultura BDA modificado (batata: $100 \mathrm{~g} / \mathrm{L}$; dextrose: $5 \mathrm{~g} /$ L; agar: $12 \mathrm{~g} / \mathrm{L}$ ) em placas de Pétri e incubadas durante 7 dias em câmara climatizada a $23 \pm 3{ }^{\circ} \mathrm{C}$. Cada componente floral pelo patógeno foi contado e os dados expressos em percentual de incidência. As coletas das inflorescências iniciaram após a emissão das panículas e continuaram até a época de colheita, perfazendo um total de seis coletas. Este experimento avaliou a incidência de $P$. chaetomioides em 2.304 placas de Pétri, que continham 10 sementes por placa, sendo 16 placas/coleta para cada genótipo testado.

\section{Infecção e formação da mancha nos grãos após o amadurecimento fisiológico}

Foram utilizados 10 genótipos de aveia branca na estação de cultivo de 2001: UFRGS 995058-3, UFRGS 998013-3, UFRGS 17, OR 2, UFRGS 18, UFRGS 99120022, UPF 95204-2, UFRGS 999007-5, UFRGS 19, UFRGS 999022-1. Com o objetivo de ampliar a amostragem dos grãos neste estudo, trabalhou-se com populações diferentes nas duas estações de cultivo. Assim, em 2002 foram usados os 14 genótipos de aveia branca UFRGS 9950583, UFRGS 9990004-2, UFRGS 998013-3, UFRGS 17, URS 20, UFRGS 18, UPF 18, UFRGS 14, UFRGS 16, URS 21, UFRGS 15, URS 22, UFRGS 19, ER 20877-2. Todos os genótipos apresentavam resistência diferenciada à infecção $\mathrm{e}$ à formação de mancha e foram colhidos em cinco épocas ( 1 =ideal; 2 =atraso de 7 dias ; 3 =atraso de quatorze dias; 4 =atraso de vinte um dias; $5=$ atraso de 30 dias). Odelineamento experimental utilizado foi o de blocos casualizados (fatorial 14 x 7), com 4 repetições de parcelas de $3 \mathrm{~m}^{2}$. As amostras dos tratamentos foram constituídas das sementes colhidas em cada parcela, das quais foram retiradas subamostras contendo 100 sementes, totalizando 400 sementes por tratamento. Para a avaliação da severidade da mancha, os grãos foram descascados e classificados em dois grupos: manchados e não-manchados. Os valores obtidos foram expressos em porcentagem de grãos manchados. O percentual de infecção foi avaliado através da incidência de $P$. chaetomioides em 400 grãos manchados de cada tratamento quando incubados sobre meio de cultura BDA modificado (batata: $100 \mathrm{~g} / \mathrm{L}$; dextrose: $5 \mathrm{~g} / \mathrm{L}$; agar: $12 \mathrm{~g} / \mathrm{L}$ ) em placas de Pétri e incubadas durante 7 dias em câmara climatizada a $23 \pm 3{ }^{\circ} \mathrm{C}$. Este experimento avaliou a incidência de $P$. chaetomioides em 2.880 placas de Pétri, sendo 40 placas para cada tratamento. Também foram realizadas avaliações de rendimento $(\mathrm{kg} / \mathrm{ha})$ e peso do hectolitro $(\mathrm{kg} / \mathrm{hl})$ dos tratamentos. Os dados metereológicos foram obtidos junto ao Departamento de Plantas Forrageiras e Agrometeorologia/ UFRGS referentes aos dois períodos de colheita.

\section{Ação do fungicida em diferentes épocas de aplicação}

A aplicação do fungicida sistêmico Tebuconazole (Concentrado Emulsionável 0,75 L de p.c./ha) em seis épocas após a exposição da panícula foi baseada na hipótese de que a utilização do produto bloquearia a infecção no período suscetível dos grãos, protegendo os componentes florais superficiais, tais como gluma, lemas e páleas, evitando a entrada de micélio e formação de manchas.

O fungicida foi aplicado nas seguintes épocas durante a formação dos grãos ( $\mathrm{L}=$ =floração; 2 =grão aquoso; 3 =grão leitoso; 4 =grão em massa mole; 5 =grão em massa; 6 =grão em massa dura) sobre 14 genótipos de aveia branca: UFRGS 995058-3, UFRGS 9990004-2, UFRGS 998013-3, UFRGS 17, URS 20, UFRGS 18, UPF 18, UFRGS 14, UFRGS 16, URS 21, UFRGS 15, URS 22, UFRGS 19, ER 20877-2. Utilizou-se um pulverizador portátil pressurizado com $\mathrm{CO}_{2}$, pressão de $60 \mathrm{dpi}$, equipado com uma barra com três bicos espaçados em $0,5 \mathrm{~m}$, que foi conduzido a $0,45 \mathrm{~m}$ acima do ápice das plantas $\mathrm{O}$ volume de calda foi de $200 \mathrm{~L} / \mathrm{ha}$ e a dose de fungicida, 0,75 p.c. L/ha, correspondendo a $150 \mathrm{~g}$ de i.a./ ha. A testemunha consistiu de uma parcela de cada genótipo testado onde não houve tratamento químico. O delineamento experimental e a metodologia utilizada para as amostragens e avaliações de infecção e incidência de $P$. chaetomioides foram semelhantes à anteriormente citada.

\section{Análise Estatística}

A análise estatística dos dados foi realizada utilizandose o programa $\mathrm{SAS}^{\circledR}$ Systems, versão 8.2, e a discriminação da variação entre tratamentos foi feita pelo teste de Tukey e Dunnet ao nível de $5 \%$ de probabilidade. A regressão utilizada foi calculada pelo programa Excel, a partir das médias colocadas na planilha (Figura 1).

\section{RESULTADOS E DISCUSSÃO}

Os 15 genótipos avaliados apresentaram grande variação para a percentagem de grãos manchados e incidência de $P$. chaetomioides em diferentes níveis de resistência com relação à mancha-negra (Tabela 1). O genótipo UFRGS 19 teve a menor incidência de $P$. chaetomioides sendo, portanto, o mais resistente. Estes resultados reforçam aqueles 


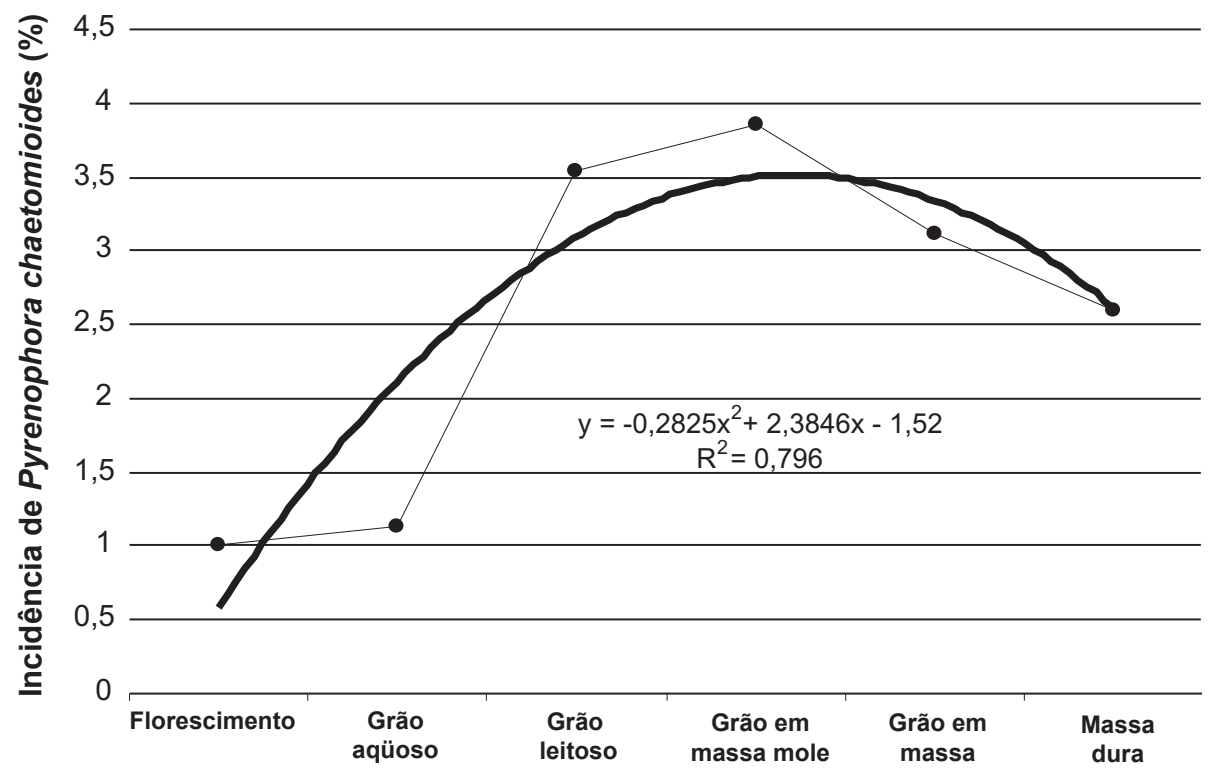

Estádios de desenvolvimento dos grãos

FIG. 1 - Incidência de Pyrenophora chaetomioides em carpelos de seis genótipos de aveia branca durante os estádios de desenvolvimento dos grãos.

obtidos por Rosa et al. (2001), que o identificaram como o mais resistente à infecção sob condições de campo em diferentes épocas de plantio. Alguns genótipos apresentaram alta percentagem de grãos manchados com incidências relativamente baixas, como UFRGS 999007-5 e UPF 16. Por outro lado, um grande número de genótipos teve uma alta percentagem de grãos manchados e alta incidência, portanto, altamente suscetíveis à doença.

TABELA 1 - Percentual visual de grãos manchados e da incidência de Pyrenophora chaetomioides em meio BDA em 15 genótipos de aveia branca

\begin{tabular}{lrlrl}
\hline \multicolumn{1}{c}{ Genótipos } & Grãos manchados(\%) & Incidência (\%) \\
\hline UFRGS 995058-3 & 83,3 & $\mathrm{a}^{1}$ & 24,6 & $\mathrm{abc}$ \\
UFRGS 999004-2 & 78,8 & $\mathrm{ab}$ & 12,4 & $\mathrm{bc}$ \\
UFRGS 998013-3 & 73,5 & $\mathrm{bc}$ & 21,0 & $\mathrm{abc}$ \\
UFRGS 17 & 72,5 & $\mathrm{bcd}$ & 29,2 & $\mathrm{abc}$ \\
UFRGS 9912002-2 & 66,8 & $\mathrm{cde}$ & $38,9 \mathrm{ab}$ \\
UFRGS 15 & $64,8 \mathrm{ef}$ & $14,1 \mathrm{bc}$ \\
UPF16 & $59,8 \mathrm{e}$ & $8,4 \mathrm{bc}$ \\
UFRGS 999007-5 & $48,0 \mathrm{f}$ & $75,8 \mathrm{a}$ \\
OR 2 & $45,5 \mathrm{f}$ & 26,7 & $\mathrm{abc}$ \\
UFRGS 999022-1 & $44,3 \mathrm{f}$ & $19,6 \mathrm{abc}$ \\
UPF 95204-2 & $42,0 \mathrm{fg}$ & $11,4 \mathrm{bc}$ \\
UFRGS 997005-2 & $35,0 \mathrm{gh}$ & $5,7 \mathrm{~cd}$ \\
UFRGS 16 & $33,5 \mathrm{gh}$ & $18,2 \mathrm{abc}$ \\
ER 20877-2 & $30,8 \mathrm{~h}$ & $26,8 \mathrm{abc}$ \\
UFRGS 19 & $13,8 \mathrm{i}$ & $1,2 \mathrm{~d}$ \\
\hline
\end{tabular}

${ }^{1}$ Médias seguidas de mesma letra não diferem significativamente pelo teste Tukey a $5 \%$.
A correlação obtida entre o percentual de grãos manchados e incidência (Tabela 1) não foi significativa ( $\mathrm{r}=$ 0,18 ). Estes resultados indicam que a natureza da resistência nos genótipos para esta moléstia englobe dois mecanismos: o de resistência à penetração do patógeno, barreira passiva que geralmente não envolve resposta do hospedeiro, e resistência ao desenvolvimento, geralmente ligada a caracteres fisiológicos da planta (Bergamin Filho \& Kimati, 1978). Logo, a resistência ao fungo, observada através do percentual de grãos manchados, parece ser mais importante que a resistência à infecção pois genótipos com altos níveis de incidência de $P$. chaetomioides apresentaram percentuais de grãos manchados semelhantes aos de baixa incidência.

A incidência de $P$. chaetomioides nos carpelos aumenta significativamente a partir do estádio de grão leitoso, atingindo valor máximo no estádio de massa e, após, decresce nos estádios seguintes até o de massa dura (Figura 1). Esses resultados não estão de acordo com os obtidos por Rosa et al. (2001) e evidenciam que o período de maior suscetibilidade para o estabelecimento deste patógeno no grão ocorre no estádio de grão leitoso e massa mole. Deste modo, o período de suscetibilidade dos grãos de aveia a $P$. chaetomioides não está restrito ao estádio de grão leitoso, como relataram Schilder \& Bergstrom (1994) para P. triticirepentis (Died.) Drechsler em trigo, e nem tão extenso quanto para $P$. graminea $\mathrm{S}$. Ito \& Kurib. em cevada, que vai desde a emissão da espiga até o estádio de massa mole (Teviotdale \& Hall, 1976). O aumento da umidade, volume e maior disponibilidade de nutrientes dos grãos ocorrem a partir de 21 dias após a polinização, que coincide com os estádios de maior suscetibilidade a $P$. chaetomioides. Com o 
crescimento dos grãos, estes podem entrar em maior contato com os demais componentes florais infectados, contribuindo para o acesso deste fungo e, assim, predispondo os grãos à infecção neste período.

Um outro fator, além do estádio de desenvolvimento dos grãos, que poderia influenciar na infecção em aveia é a densidade de inóculo presente a campo. Rosa (2002) constatou maior produção de conídios de $P$. chaetomioides também nestes estádios de maior infecção, em torno de 12 a $28 \times 10^{5}$ conídios produzidos por grama de massa seca das folhas basais mortas.

A maior incidência de $P$. chaetomioides ocorre nos componentes florais mais externos, glumas, páleas e lemas, do que nos carpelos, nos estádios iniciais (florescimento e grão aquoso) (Figura 2). Isto pode sugerir que a infecção dos carpelos esteja na dependência da infecção dos componentes florais externos. As características morfológicas da semente de aveia dificilmente permitiriam contato direto dos esporos de $P$. chaetomioides com o grão. Conseqüentemente, estes precisam penetrar e colonizar sucessivamente, via proliferação micelial, gluma, lema e pálea, sendo estas as barreiras físicas iniciais para a formação da mancha. A gluma, apesar apresentar maiores valores de incidência de $P$. chaetomioides, parece contribuir menos na infecção que a lema e a pálea, já que a mesma não está aderida ao grão (Bocchese et al., 2003).

A redução da presença do patógeno (Figuras 1 e 2) no estádio de massa dura pode ser explicada pela inibição por outros microrganismos, tal como Fusarium graminearum Schwabe, fato observado também com alta freqüência nos últimos estádios de desenvolvimento das sementes (Rosa et al., 2003).
A incidência de $P$. chaetomioides nas diferentes épocas de colheita na estação de cultivo de 2001 não apresentou diferença significativa (Tabela 2). Entretanto, houve aumento significativo no percentual de grãos manchados com o atraso da colheita. Em 2002, o atraso na colheita aumentou a incidência e o percentual de grãos manchados. Entre as duas estações de cultivo do experimento foram observadas grandes diferenças na precipitação pluviométrica, ocorrida após a época correta da colheita, sendo que em 2001, houve uma precipitação acumulada de $84,2 \mathrm{~mm}$ enquanto que, em 2002, para o mesmo período, foi de $286,7 \mathrm{~mm}$. Já as temperaturas média e máxima não apresentaram diferenças nos dois anos de cultivo.

Rosa (2002) relatou que o aumento da produção de conídios de $P$. chaetomioides é fortemente influenciado pela precipitação. Além disso, a umidade elevada favorece a disseminação e preenche um dos requerimentos essenciais para germinação dos conídios logo após a sua deposição na superfície do hospedeiro (Agrios, 1997). Logo, a maior precipitação ocorrida nas épocas de colheita em 2002 pode ter favorecido o aumento de incidência de P. chaetomioides.

Considerando o aumento do percentual de grãos manchados nas duas estações de cultivo, pode-se inferir que as infecções oriundas do período de maior suscetibilidade à $P$. chaetomioides sejam a principal causa do aumento de formação de manchas nos grãos após a maturação. Basicamente, porque garante a presença do micélio presente no pericarpo que, sob condições ambientais favoráveis, particularmente temperaturas amenas e alta umidade relativa, pode vir a colonizar mais intensamente os tecidos da superfície dos grãos.

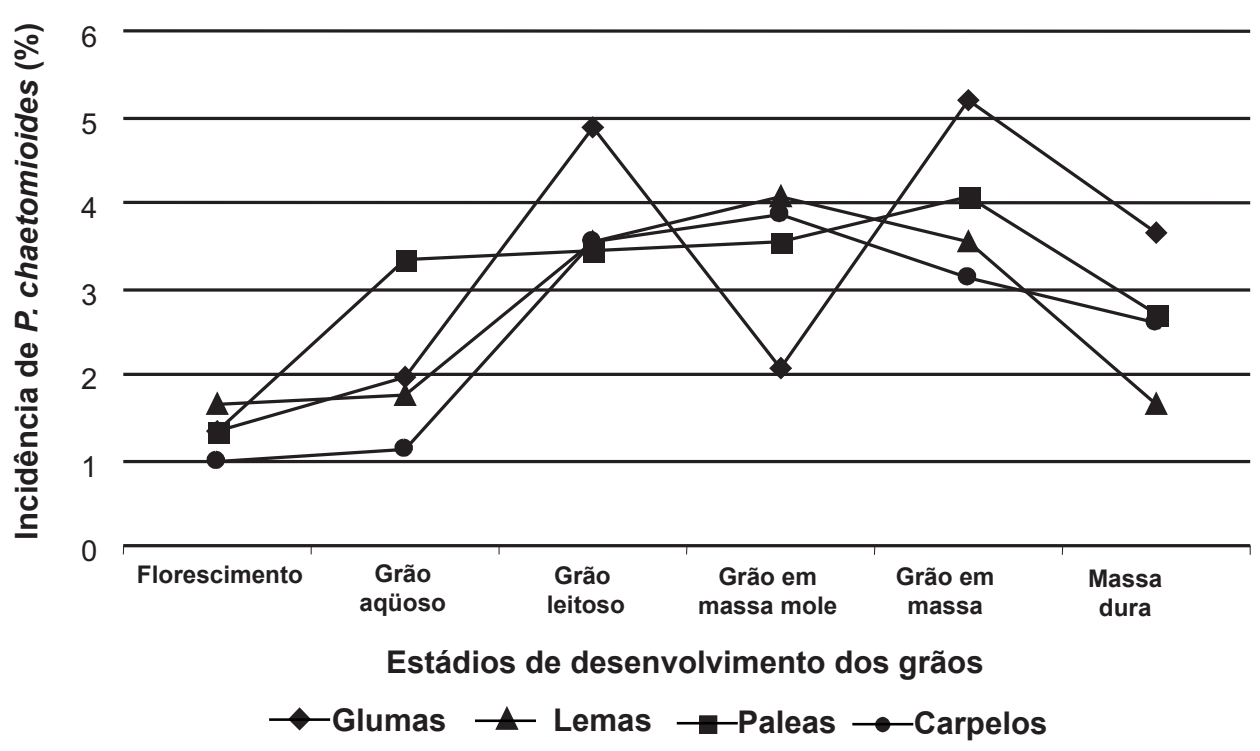

FIG. 2 - Incidência de Pyrenophora chaetomioides nos componentes florais de cultivares aveia branca, quando plaqueados em meio de cultura (BDA). 
A aplicação de fungicida nos diferentes estádios de formação dos grãos não influenciou no rendimento e na percentagem de grãos manchados. O peso do hectolitro, por sua vez, mostrou uma melhora significativa somente quando as pulverizações com o fungicida foram feitas nas épocas de floração e grão aquoso enquanto que, a incidência de $P$. chaetomioides, somente foi reduzida significativamente quando o fungicida foi aplicado na floração (Tabela 3).

De um modo geral, a aplicação de fungicida se mostrou pouco eficiente. Seu efeito foi apenas observado na diminuição da incidência do fungo no período de floração e, no aumento do $\mathrm{pH}$, nos períodos de floração e grão aquoso. Nos demais tratamentos não houve diferenças significativas em relação à testemunha. Apesar do tebuconazole ser um fungicida sistêmico e recomendado para o tratamento da mancha foliar em aveia, ocasionada por $P$. chaetomioides, não se mostrou eficiente para o tratamento desta moléstia nos grãos. Forcelini (1994) relatou que o movimento do ingrediente ativo deste fungicida pode ser limitado em frutos e folhas jovens devido à reduzida transpiração. É possível que tal fato também seja responsável pela ineficiência do mesmo para o controle de $P$. chaetomioides em panículas de aveia.

Blum et al. (1998) não observaram efeito do mesmo fungicida no tratamento da parte aérea, mesmo quando associado com o tratamento de sementes, sobre a incidência do fungo na semente colhida. Rosa (2002) utilizou apenas tratamentos foliares com tebuconazole aplicados a cada sete dias durante o desenvolvimento das sementes em uma estação de cultivo de aveia e observou a maior redução de incidência de $P$. chaetomioides, em relação à testemunha, quando o produto foi aplicado durante o estádio de grão em massa mole.

A introdução de aplicação adicional de fungicida no manejo da mancha-negra para utilização pelos produtores depende da sua relação custo/benefício. $\mathrm{O}$ valor de uma aplicação de fungicida é de aproximadamente US\$30,00 /ha, que corresponde a aproximadamente $300 \mathrm{~kg}$ de grãos de aveia branca (Martinelli et al., 2003). Logo, para que seja viável economicamente, é necessário que o aumento no rendimento seja maior que $300 \mathrm{~kg}$ e que reduza em mais de $50 \%$ no percentual de grãos manchados para justificar sua utilização.

A aplicação adicional de tebuconazole para o controle da mancha-negra parece não ser viável economicamente, uma vez que a aplicação de fungicida na floração, em relação a testemunha, reduziu apenas $21 \%$ da incidência do fungo nas sementes. Além disso, não foi suficiente para reduzir a formação de manchas e nem produzir aumento significativo no rendimento que compensasse o aumento de custo do tratamento químico (Tabela 3).

TABELA 2 - Percentual visual de grãos manchados e incidência de Pyrenophora chaetomioides em meio BDA em genótipos de aveia branca, avaliados em épocas diferentes de colheita, em 2001 e 2002

\begin{tabular}{|c|c|c|c|}
\hline Ano & $\begin{array}{c}\text { Épocas } \\
\text { de colheita }\end{array}$ & $\begin{array}{c}\text { Grãos } \\
\text { manchados (\%) }\end{array}$ & $\begin{array}{c}\text { Incidência de } \\
\text { P. chaetomioides (\%) }\end{array}$ \\
\hline \multirow{5}{*}{2001} & Época correta & $58,7 \quad \mathrm{c}^{*}$ & $66,6 \quad a^{*}$ \\
\hline & Atraso de 7 dias & 68,7 & 72,0 \\
\hline & Atraso de 14 dias & 70,5 & 67,6 \\
\hline & Atraso de 21 dias & 71,0 & 68,2 \\
\hline & Atraso de 30 dias & 74,6 & 68,7 \\
\hline \multirow{3}{*}{2002} & Época correta & 40,7 & 16,3 \\
\hline & Atraso de 7 dias & 47,7 & 16,5 \\
\hline & Atraso de 14 dias & 48,9 & 27,0 \\
\hline
\end{tabular}

*Médias seguidas de mesma letra na coluna não diferem entre si pelo teste Tukey a 5\%.

TABELA 3 - Incidência de Pyrenophora chaetomioides em grãos de aveia branca, rendimento $(\mathrm{kg} / \mathrm{ha})$, peso do hectolitro $(\mathrm{kg} / \mathrm{hl})$ e percentual de grãos manchados em seis épocas de aplicação de fungicida, na EEA/UFRGS, 2002

\begin{tabular}{|c|c|c|c|c|c|c|c|}
\hline \multirow{2}{*}{$\begin{array}{l}\begin{array}{c}\text { Épocas da Aplicação } \\
\text { do Fungicida }\end{array} \\
\text { Testemunha }\end{array}$} & $\begin{array}{l}\text { Incidência }(\%) \text { de } \\
\text { P. chaetomioides } 1\end{array}$ & \multicolumn{2}{|c|}{$\begin{array}{c}\text { Rendimento } \\
(\mathrm{kg} / \mathrm{ha})^{1}\end{array}$} & \multicolumn{2}{|c|}{$\underset{(\mathrm{kg} / \mathrm{hl})^{1}}{\mathrm{PH}}$} & \multicolumn{2}{|c|}{$\begin{array}{c}\text { Grãos } \\
\text { Manchados (\%) }\end{array}$} \\
\hline & 22,0 & 2577 & $\mathrm{~ns}^{2}$ & 47,2 & & 45,5 & $\mathrm{~ns}^{2}$ \\
\hline Floração & 17,3 & 2749 & ns & 48,7 & 3 & 43,7 & ns \\
\hline Grão aquoso & 18,4 & 2782 & ns & 49,6 & 3 & 42,1 & ns \\
\hline Grão leitoso & 21,8 & 2585 & ns & 47,7 & & 44,3 & ns \\
\hline Grão em massa & 21,2 & 2617 & ns & 47,3 & & 45,2 & ns \\
\hline Grão em massa mole & 20,6 & 2568 & ns & 46,6 & & 44,1 & ns \\
\hline Grão em massa d ura & 19,0 & 2513 & ns & 46,1 & & 43,7 & ns \\
\hline Média & 20,0 & 2627 & & 47,6 & & 44,1 & \\
\hline $\mathrm{CV} \%$ & 34,8 & 9,8 & & 26,4 & & 11,6 & \\
\hline
\end{tabular}

${ }^{1}$ Os valores apresentados nesta tabela representam as médias de 14 genótipos para cada tratamento com fungicida.

${ }^{2} \mathrm{~ns}=$ não significativo pelo teste de Tukey a $5 \%$.

${ }^{3}$ Médias significativamente diferentes da testemunha, quando comparadas pelo teste Dunnet a $5 \%$. 


\section{AGRADECIMENTOS}

A CAPES pela concessão da bolsa de doutorado à primeira autora.

\section{REFERÊNCIAS BIBLIOGRÁFICAS}

AGRIOS, G. N. Plant Pathology. 4 ed. New York. Academic Press. 1997.

BERGAMIN FILHO, A. \& KIMATI, H. Variedades resistentes. In: Galli, F. (Ed.) Manual de Fitopatologia, vol 1. 2.ed. São Paulo SP. Agronômica Ceres. 1978. pp. 297-313.

BLUM, M.M.C., ALMEIDA, J.L. \& REIS, E.M. Avaliação da incidência da Helmintosporiose da aveia na parte aérea da cultura da aveia e semente colhida. Resumos, 18. Reunião da Comissão Sul-Brasileira de Pesquisa de Aveia, Londrina PR. 1998. p. 25-30.

BOCCHESE, C.A.C. Pyrenophora avenae: especificidade a tecido, análise enzimática e de virulência. (Dissertação de Mestrado) Universidade Federal do Rio Grande do Sul, Porto Alegre. 2000.

BOCCHESE, C.A.C., MARTINELLI, J.A., MATSUMURA, A.T.S., FEDERIZZI, L.C. \& PRESTES, A.M. Virulência, atividade enzimática e padrões de isoesterases de Pyrenophora chaetomioides, agente etiológico da mancha de grãos e folhas de aveia. Fitopatologia Brasileira 28:11-16. 2003.

BOCCHESE, C.A.C., MARTINELLI, J.A., MATSUMURA, A.T. ., FEDERIZZI, L.C., DRESCH, L.F. \& TELLIER, M. Especificidade de Pyrenophora avenae aos tecidos da semente de Avena sativa e sua atividade enzimática. Fitopatologia Brasileira 26:180-184. 2001.

CAMARGO, M.N., KLAMT, E. \& KAUFFMAN, J.H. Classificação de solos usada em levantamentos pedológicos no Brasil. Boletim Informativo da Sociedade Brasileira de Ciência do Solo 12:11-33. 1987.

CBPA. Recomendações tecnológicas para a cultura da aveia. Passo Fundo PR. Universidade de Passo Fundo. 2003.

FORCELINI, C.A. Fungicidas inibidores da síntese de esteróis. I. Triazoles. Revisão Anual de Patologia de Plantas 2:335-355. 1994.

LÂNGARO, C.L., MORAIS, M.G., PRESTES, A.M., MARTINELLI, J.A. \& MATSUMURA, A.T.S. O uso de cultivares resistentes no controle da helmintosporiose da aveia. Resumos, 20.
Reunião da Comissão Sul-Brasileira de Pesquisa de Aveia, Pelotas RS. 2000. p. 160-161.

MARTINELli, J.A., BOCCHESE, C.A.C., ROSA, C.R.E. \& FEDERIZZI, L.C. Avaliação de cultivares e linhagens de aveia branca quanto à porcentagem de mancha, rendimento e peso do hectolitro em diferentes épocas de colheita. Resumos, 23. Reunião da Comissão Brasileira de Pesquisa de Aveia, Gramado RS. 2003. 1CD-ROM.

MELLO, D., LEMOS, R.C, ABRÃO, P.U.R. Levantamento em série dos solos do centro agronômico. Porto Alegre RS. Faculdade de Agronomia e Veterinária da UFRGS. 1996. p. 7-155. (Relatório Técnico Científico, 8).

ROSA, C. R.E. Estabelecimento de Pyrenophora avenae Ito \& Kurib em grãos de aveia (Avena sativa L.) em formação sob condições de campo. (Dissertação de Mestrado) Universidade Federal do Rio Grande do Sul. Porto Alegre RS. 2002.

ROSA, C.R.E., MARTINELLI, J.A., FEDERIZZI, L.C. \& BOCCHESE, C.A.C. Correlação entre a severidade nas folhas e incidência de Pyrenophora avenae nos grãos de genótipos de aveia branca. Resumos, 23. Reunião da Comissão Brasileira de Pesquisa de Aveia, Gramado RS. 2003. 1 CD-ROM.

ROSA, C.R.E., MARTINELLI, J.A., FEDERIZZI, L.C. \& BOCCHESE, C.A.C. Infecção de sementes por Pyrenophora avenae Ito \& Kurib. a partir da emergência das inflorescências sob condições de campo. Resumos, 21. Reunião da Comissão Brasileira de Pesquisa de Aveia, Lages SC. 2001. p. 141-142.

SABESTA, J., ZWARTZ, B., HARDER, D.E., CORAZA, L., RODERICH, H.W. \& STOJANOVIC, S. Incidence and resistence of oats to fungus diseases in Europe in 1988-1994. Ochrona Roslin 32:103-113. 1996.

SCHILDER, A.M.C. \& BERGSTROM, G.C. Infection of wheat seed by Pyrenophora tritici-repentis. Canadian Journal of Botany 72:510-519. 1994.

TEVIOTDALE, B.L. \& HALL, D.H. Factors affecting inoculum development and seed transmission of Helminthosporium graminearum. Phytopathology 66:295-301. 1976.

TURNER, D.M. \& MILLARD, W.A. Leaf-spot of oats, Helminthosporium avenae (Bri. \& Cav,) Eid. Annals Applied Biology 18:535-559. 1931. 